\title{
Role of hepcidin in recombinant human erythropoietin therapy resistance among chronic hemodialysis patients
}

\author{
Abdelnaser Badawy ${ }^{1,}$ Emad El-Masry ${ }^{2}$, and Ashraf Hussein ${ }^{3}$ \\ ${ }^{1}$ Biochemistry Department, Faculty of Medicine, Mansoura University, Egypt. \\ ${ }^{2}$ Clinical Pathology Department, Faculty of Medicine, Mansoura University, Egypt. \\ ${ }^{3}$ Internal Medicine Department, Faculty of Medicine, Mansoura University, Egypt
}

\begin{abstract}
:
Objective: To assess the role of hepcidin in recombinant human erythropoietin (rhEPO) therapy resistance among chronic hemodialysis patients

Methods: This study included 43 maintenance hemodialysis (HD) patients under rhEPO treatment for a median time period of 18 months and 20 healthy volunteers as a control group. The HD patients included 22 responders and 21 non-responders to rhEPO therapy. In all patients and controls; hemoglobin $(H b)$ concentration, Serum iron, serum ferritin, Serum C-reactive protein (CRP), serum IL-6 \& Serum hepcidin levels were measured.

Results: Compared to controls, HD patients presented with lower mean Hb concentration, higher mean serum ferritin, mean CRP, mean IL-6, and mean hepcidin serum levels [all are $p<0.001]$. Among HD patients; nonresponders had lower mean $\mathrm{Hb}$, higher mean rhEPO dose, higher mean CRP levels and also higher mean IL- 6 levels. Mean hepcidin serum levels among non-responders were significantly higher than among responders [all are $p<0.001]$. Multiple regression analysis showed that ERI, ferritin, CRP, and IL- 6 as an independent variables were significantly associated with hepcidin serum levels $(r=0.756 ; p<0.001, r=0.921 ; p<0.001$, $r=0.732 ; p=0.002 \& r=0.807 ; p<0.001$ respectively).

Conclusion: Serum hepcidin level could be considered as a marker of rhEPO treatment resistance in maintenance hemodialysis patients.
\end{abstract}

Key words: Recombinant erythropoietin, Resistance, Maintenance Hemodialysis, Hepcidin

\section{Introduction}

Anaemia is a common complication in maintenance hemodialysis (HD) patients and contributes to reduced quality of life [1]. Despite the great success of recombinant human erythropoietin (rhEPO) in clinical practice for the treatment of anaemia in dialysis patients, resistance to this therapy is approximately $10-20 \%$ [2]. Erythropoietin (EPO) resistance, defined as an inadequate bone marrow response to exogenous or endogenous EPO, contributes importantly to anaemia [3].

Hepcidin is a protein closely related to iron homeostasis, and is an acute-phase protein mainly produced in the liver. Hepcidin inhibits the efflux of iron into plasma transferrin by down regulating ferroportin, the efflux channel for iron in macrophages and in enterocytes [4]. Enhanced synthesis of hepcidin thus leads to inhibition of iron absorption in the small intestine and sequestering of iron in macrophages, resulting in limited iron availability for erythropoiesis [5]. Increased iron stores and inflammation induce hepcidin synthesis in the liver, whereas suppression occurs during hypoxia, iron deficiency, and increased erythropoiesis [6].

Hepcidin thus integrates the input from both inflammatory and erythropoietic pathways. The role of hepcidin levels, a key regulator of iron homeostasis, in rhEPO resistance in patients on maintenance hemodialysis still controversy. So, we plan, to study the relationship between hepcidin serum levels and rhEPO resistance in HD patients

\section{1, Subjects}

\section{Subjects and Methods:}

We selected 43 maintenance HD patients (21 males, 22 females; mean age $49.37 \pm 9.85$ years) under rhEPO treatment for a median time period of 18 months. All patients used the high-flux polysulfone dialyzer from Gambro Company (Hechingen, Germany). The HD patients included 22 responders and 21 non-responders to rhEPO therapy. Classification of HD patients, as responders or non-responders, was performed in accordance with the European Best Practice Guidelines (3). The mean rhEPO maintenance dose for responder patients was $189.44 \pm 55.39 \mathrm{U} / \mathrm{kg} /$ week and for non-responders it was $314.47 \pm 10.78 \mathrm{U} / \mathrm{kg} /$ week. We calculated an EPO responsiveness index (ERI), as described in previous studies [7], defined as the weekly EPO dose divided by $\mathrm{Hb}$ level (g/dl). Both the EPO dose and ERI were divided by target body weight to indicate the required EPO dose per kilogram of dry body weight. The 2 groups of patients were matched for age, gender, weight, mean time on 
$\mathrm{HD}, \mathrm{Kt} / \mathrm{V}$ (a number used to quantify hemodialysis treatment adequacy) and parathyroid hormone serum levels. Duration of HD was calculated \& the mean ultra filtration (UF) was calculated also.

Patients with autoimmune diseases, malignancy, hematological disorders, acute or chronic infection and history of blood transfusion within the last 6 months were excluded from the study. Healthy volunteers $(n=$ 20) with normal hematological and biochemical values and without any history of renal or inflammatory disease were used as normal controls. They were age and gender matched with HD patients.

\section{2, Methods:}

In all patients and controls, hemoglobin $(\mathrm{Hb})$ levels, were measured by using an automatic blood cell counter (Sysmex K1000; Sysmex, Hamburg, Germany). Serum iron concentration was determined using a colorimetric method (iron; Randox Laboratories Ltd., Crumlin, UK), whereas serum ferritin (Randox Laboratories) was measured by immunoturbidimetry. Calculation of serum transferring saturation (TSAT) was carried out; (The transferrin saturation (TSAT) test is the ratio of serum iron and total iron-binding capacity. Transferrin saturation measures how much iron is bound to transferrin and is readily available to make red blood cells. In healthy people, between 20 and 50 percent of available transferrin sites are saturated with iron). Serum calcium (corrected for albumin), serum phosphorus, serum albumin \& iPTH serum levels were measured.

\subsection{1, Serum Hepcidin Measurement}

Quantitative measurement of bioactive hepcidin in serum was carried out using a sensitive competitive ELISA [8]. Briefly, samples were diluted appropriately, mixed with a biotinylated hepcidin analog (tracer), and added to 96-well micro titer plates coated with rabbit anti-hepcidin antibodies for $2 \mathrm{~h}$. After binding, wells were washed three times with $0.05 \%$ Tween 20 in tris-buffered saline (pH 8), and horseradish peroxidase - avidin secondary reagent ( $1 \mathrm{ng} / \mathrm{l}$ ) was added and allowed to bind for $1 \mathrm{~h}$. Wells were washed three times with $0.05 \%$ Tween 20 in tris-buffered saline, tetramethyl benzadine substrate was added, and the reactions were stopped with $1 \mathrm{~N}$ sulfuric acid. Optical density of reactions at $450 \mathrm{~nm}$ was determined on a Beckman Coulter DTX 880 detector. Sample concentrations were determined using Prism curve-fitting software by comparison to a standard curve generated using synthetic hepcidin. Synthetic hepcidin standards were produced by Bachem Biosciences, Inc. (King of Prussia, PA) and validated using HPLC, peptide sequencing, mass spectroscopy, and bioactivity studies conducted in HEK293 cells over expressing ferroportin-green fluorescent protein.

\subsection{2, Serum IL-6 Measurement}

The GenWay IL-6-EASIA is a solid phase Enzyme Amplified Sensitivity Immunoassay performed on microtiterplate. The assay uses monoclonal antibodies (MAbs) directed against distinct epitopes of IL-6. Calibrators and samples react with the capture monoclonal antibody (MAb 1) coated on microtiter well and with a monoclonal antibody (MAb 2) labelled with horseradish peroxidase (HRP). After an incubation period allowing the formation of a sandwich: coated MAb 1 - human IL-6 - MAb 2 - HRP, the microtiterplate is washed to remove unbound enzyme labelled antibody. Bound enzymelabelled antibody is measured through a chromogenic reaction. Chromogenic solution (TMB) is added and incubated. The reaction is stopped with the addition of Stop Solution and the microtiterplate is then read at the appropriate wavelength. The amount of substrate turnover is determined colourimetrically by measuring the absorbance, which is proportional to the IL6 concentration. A calibration curve is plotted and IL-6 concentration in samples is determined by interpolation from the calibration curve. The use of the EASIA reader (linearity up to 3 OD units) and a sophisticated data reduction method (polychromatic data reduction) result in a high sensitivity in the low range and in an extended calibration range (http://www.genwaybio.com/elisas/human-IL-6-elisa-kit).

\subsection{3, Serum CRP Measurement}

Serum was mixed with Intralipid 20\% in Tris-calcium buffer (pH 7.5). After 30 min of incubation at 37 degrees C, the CRP-phospholipids complexes were measured by turbidimetry $(660 \mathrm{~nm} / 700 \mathrm{~nm})$ with a Cobas 6000 analyzer (Roche). Results were compared with those obtained using a typical immunoturbidimetric method (Roche) [9].

\section{3, Statistical methods:}

The Data were analyzed by computer using the statistical package SPSS for windows version 16 (software). Quantitative variables were reported as mean $+/-\mathrm{SD}$, and qualitative variables as number and/or percentages. Comparing means was performed by independent samples $\mathrm{T}$ test. Correlations between different parameters were determined by bivariate Pearson correlation test. The linear relationship between variables was assessed by linear regression analysis. To determine independent factors ( $\mathrm{Hb}$ concentration, serum ferritin, CRP and interleukin 6, and weekly rhEPO dose) affecting hepcidin serum levels; Multivariate analysis was done using stepwise logistic regression. For all tests $\mathrm{P}$ values $<0.05$ were considered statistically significant. 


\section{Results:}

Compared to controls, HD patients presented with significantly lower mean $\mathrm{Hb}$ concentration $(10.20 \pm 1.33$ vs. $13.73 \pm 1.17 \mathrm{~g} / \mathrm{dl}, \mathrm{p}<0.001)$, and significantly higher mean serum ferritin $(513.25 \pm 364.40$ $\mathrm{ng} / \mathrm{ml}$ ) vs. $124.08 \pm 68.55 \mathrm{ng} / \mathrm{ml}), \mathrm{p}<0.001]$, and mean serum transferring saturation was statistically significantly higher in HD patients compared to controls $(22.75 \pm 6.21 \mathrm{vs} .35 .84 \pm 17.99 \%, \mathrm{p}=0.002)($ Table 1$)$. Mean CRP $(6.18 \pm 3.96 \mathrm{mg} / \mathrm{l})$ vs. $(1.38 \pm 0.44 \mathrm{mg} / \mathrm{l}), \mathrm{p}<0.001]$, mean IL-6 [6.73 $\pm 3.86 \mathrm{pg} / \mathrm{ml}$ vs. $1.34 \pm 0.47 \mathrm{pg} / \mathrm{ml}$, $\mathrm{p}<0.001]$, mean hepcidin levels [305.01 $\pm 160.94 \mathrm{ng} / \mathrm{ml} \quad$ vs. $111.35 \pm 45.72 \mathrm{ng} / \mathrm{ml}, \mathrm{p}<0.001]$.

Among HD patients, non-responders had lower mean $\mathrm{Hb}(8.89 \pm 0.64$ vs. $11.16 \pm 0.67 \mathrm{~g} / \mathrm{dl}, \mathrm{p}<0.001)$, higher mean rhEPO dose $(314 \pm 10.78$ vs. $189.44 \pm 55.39 \mathrm{U} / \mathrm{kg} /$ week, $\mathrm{p}<0.000)$, higher mean ERI $(35.55 \pm$ 2.42 VS. $16.88 \pm 4.46$ ), higher mean CRP levels [9.39 $\pm 2.85 \mathrm{mg} / \mathrm{l}$ vs. $3.11 \pm 1.87 \mathrm{mg} / \mathrm{l}, \mathrm{p}<0.001]$ and also higher mean IL- 6 levels $(9.96 \pm 2.65 \mathrm{pg} / \mathrm{ml}$ VS $3.65 \pm 1.67 \mathrm{pg} / \mathrm{ml}, \mathrm{P}<0.001)$. Regarding iron status markers; there were statistically significant differences found between responder and non-responder patients (Table2).

Mean hepcidin serum levels among non-responders were significantly higher than among responders $[446.27 \pm 83.86$ vs. $170.18 \pm 78.16 \mathrm{ng} / \mathrm{ml}, \mathrm{P}<0.001]$, but were higher than those in the control group. A statistically significant correlation was found between mean hepcidin serum levels and mean hemoglobin level, rhEPO dose and ERI $(\mathrm{P}<0.001)$. \& also some iron status markers show significant correlation with hepcidin serum levels [s. ferritin \& transferrin saturation P < 0.001) and inflammatory markers $[\mathrm{CRP}(\mathrm{P}<0.001)$ and interleukin 6 ( $\mathrm{P}<0.001)$ ](Table $2 \&$ fig. 1,2,3,4,5\&6).

Multiple regression analysis showed that ferritin, CRP, and IL- 6 as an independent variables were significantly associated with hepcidin serum levels $(\mathrm{r}=0.921 ; \mathrm{p}<0.001, \mathrm{r}=0.732 ; \mathrm{p}=0.002 \& \mathrm{r}=0.807 ; \mathrm{p}=$ 0.001 respectively) ( Table 3 ).

Table 1: Demographic And Laboratory Data In Maintenance Hemodialysis Patients And The Healthy Subjects

\begin{tabular}{|c|c|c|c|}
\hline Parameters & Patients & Controls & $P$ value \\
\hline Gender(male/female ratio) $\%$ & $48.8 / 51.2$ & $50 / 50$ & NS \\
\hline Age (year) & $49.37 \pm 9.8$ & $46.6 \pm 8.14$ & NS \\
\hline Body weight $(\mathrm{Kg})$ & $63.97 \pm 8.65$ & $61.75 \pm 8.09$ & NS \\
\hline Hemoglobin $(\mathrm{gm} / \mathrm{dl})$ & $10.20 \pm 1.33$ & $13.74 \pm 1.17$ & $<0.001$ \\
\hline S. Iron $(\mu \mathrm{g} / \mathrm{dl})$ & $92.44 \pm 34.49$ & $73.60 \pm 15.22$ & 0.023 \\
\hline S. Ferritin $(\mathrm{ng} / \mathrm{ml})$ & $513.25 \pm 364.4$ & $124.08 \pm 68.55$ & $<0.001$ \\
\hline TSAT $(\%)$ & $35.85 \pm 17.99$ & $22.75 \pm 6.21$ & 0.002 \\
\hline S. Hepcidin(ng/ml) & $305.01 \pm 160.94$ & $111.35 \pm 45.72$ & $<0.001$ \\
\hline $\mathrm{IL}-6(\mathrm{pg} / \mathrm{ml})$ & $6.74 \pm 3.87$ & $1.34 \pm 0.47$ & $<0.001$ \\
\hline $\mathrm{CRP}(\mathrm{mg} / \mathrm{l})$ & $6.18 \pm 3.97$ & $1.38 \pm 0.44$ & $<0.001$ \\
\hline S. Albumin $(\mathrm{gm} / \mathrm{l})$ & $3.84 \pm 0.38$ & $4.53 \pm 0.40$ & $<0.001$ \\
\hline S. Ca $(\mathrm{mg} / \mathrm{dl})$ & $8.44 \pm 0.61$ & $8.98 \pm 1.08$ & 0.015 \\
\hline S. PO4 (mg/dl) & $5.28 \pm 1.15$ & $4.07 \pm 0.61$ & $<0.001$ \\
\hline iPTH $(\mathrm{pg} / \mathrm{ml})$ & $252.10 \pm 81.79$ & $40.40 \pm 12.53$ & 0.000 \\
\hline
\end{tabular}

Kg. Kilogram; gm. gram; dl. Deciliter; S. serum; $\mu$ g, microgram; ml. milliliter; $\%$, hundred percent; ng, nanogram; Pg, picogram; L, liter; TSAT, transferrin saturation; CRP, C reactive protein; IL-6, interleukin-6; $\mathrm{Ca}$, calcium; $\mathrm{PO} 4$, phosphorus 
Table 2: Univariate Analysis Of The Association (Independent T Test) And Pearson Correlation Between Serum Hepcidin Level And Clinical \& Laboratory Parameters Among Responders \& Non Responders’ Hemodialysis Patients.

\begin{tabular}{|c|c|c|c|c|c|}
\hline \multirow[t]{2}{*}{ Parameters } & \multirow{2}{*}{$\begin{array}{l}\text { Responders } \\
\text { Mean } \pm \text { SD }\end{array}$} & \multirow{2}{*}{$\begin{array}{l}\text { Non responders } \\
\text { Mean } \pm \mathrm{SD}\end{array}$} & \multicolumn{2}{|c|}{ Pearson correlation } & \multirow[t]{2}{*}{$\mathrm{P}$ value } \\
\hline & & & coefficient(r) & $\mathrm{P}$ value & \\
\hline Age (year) & $50.18 \pm 9.86$ & $48.52 \pm 9.9$ & 0.113 & NS & NS \\
\hline Body weight(kg) & $66.26 \pm 9.97$ & $65.19 \pm 11.65$ & 0.113 & NS & NS \\
\hline Hemoglobin $(\mathrm{gm} / \mathrm{dl})$ & $11.16 \pm 0.67$ & $8.89 \pm 0.64$ & 0.795 & $<0.001$ & $<0.001$ \\
\hline EPO dose(unit//week) & $189.44 \pm 55.39$ & $314.47 \pm 10.78$ & 0.884 & $<0.001$ & $<0.001$ \\
\hline ERI (units/kg/week/Hb) & $16.88 \pm 4.46$ & $35.55 \pm 2.43$ & 0.756 & $<0.001$ & $<0.001$ \\
\hline S. Hepcidin(ng/ml) & $170.18 \pm 78.16$ & $446.27 \pm 83.86$ & & & $<0.001$ \\
\hline S. Iron $(\mu \mathrm{g} / \mathrm{dl})$ & $76.31 \pm 29.08$ & $109.33 \pm 32.00$ & 0.342 & 0.025 & 0.002 \\
\hline Iron dose $(\mathrm{mg})$ & $211.36 \pm 26.42$ & $373.80 \pm 152.98$ & 0.502 & 0.001 & $<0.001$ \\
\hline S. Ferritin (ng/l) & $208.96 \pm 146.46$ & $832.03 \pm 218.59$ & 0.921 & $<0.001$ & $<0.001$ \\
\hline TSAT $(\%)$ & $24.13 \pm 13.04$ & $48.11 \pm 13.86$ & 0.812 & $<0.001$ & $<0.001$ \\
\hline CRP (ml/1) & $3.11 \pm 1.87$ & $9.39 \pm 2.85$ & 0.732 & $<0.001$ & $<0.001$ \\
\hline $\mathrm{IL}-6(\mathrm{pg} / \mathrm{ml})$ & $3.65 \pm 1.67$ & $9.96 \pm 2.85$ & 0.807 & $<0.001$ & $<0.001$ \\
\hline iPTH $(\mathrm{pg} / \mathrm{ml})$ & $250.17 \pm 30.09$ & $265.42 \pm 26.45$ & 0.185 & NS & NS \\
\hline S. Albumin (gm/l) & $40.09 \pm 0.27$ & $35.81 \pm 0.30$ & -0.535 & $<0.001$ & $<0.001$ \\
\hline Duration of dialysis (year) & $5.31 \pm 2.07$ & $5.61 \pm 2.25$ & 0.346 & 0.023 & NS \\
\hline Ultrafilteration $(\mathrm{kg})$ & $2.84 \pm 0.76$ & $2.42 \pm 0.63$ & -0.398 & 0.008 & NS \\
\hline $\mathrm{Kt} / \mathrm{V}$ & $1.38 \pm 0.22$ & $1.41 \pm 0.16$ & 0.881 & NS & NS \\
\hline
\end{tabular}

ERI, erythropoiesis responsive index

Table 3: Linear Regression Analysis Showing The Laboratory Parameters With A Significant Independent Association With Hepcidin Serum Level In Maintenance HD Patients

\begin{tabular}{|l|l|l|c|}
\hline Independent variables & $\begin{array}{l}\text { Un standardized } \\
\beta \text {-Co- efficient }\end{array}$ & $\begin{array}{l}\text { Standardized } \\
\beta \text {-Co-efficient }\end{array}$ & P value \\
\hline Hemoglobin level & -0.007 & -0.795 & $<0.001$ \\
\hline S. iron level & 0.073 & 0.342 & 0.025 \\
\hline S. ferritin & 2.086 & 0.921 & $<0.001$ \\
\hline TSAT & 0.091 & 0.812 & 0.001 \\
\hline CRP & 0.018 & 0.732 & 0.002 \\
\hline IL- 6 & 0.019 & 0.827 & $<0.001$ \\
\hline Iron dose & 0.421 & 0.502 & 0.001 \\
\hline S. Albumin $(\mathrm{gm} / \mathrm{l})$ & 0.481 & -0.576 & 0.001 \\
\hline Kt/V & 2.86 & 0.023 & $\mathrm{NS}$ \\
\hline
\end{tabular}

$\mathrm{Hb}$

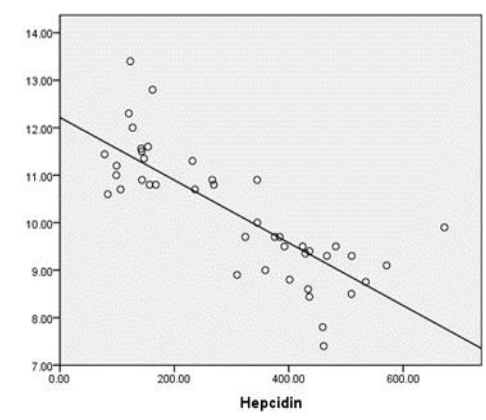

- $\begin{gathered}\text { Coserved } \\ \text { Linex }\end{gathered}$

$r=-0.795$

$\mathrm{P}<0.001$

Figure 1: Correlation between hepcidin serum levels $\&$ hemoglobin levels

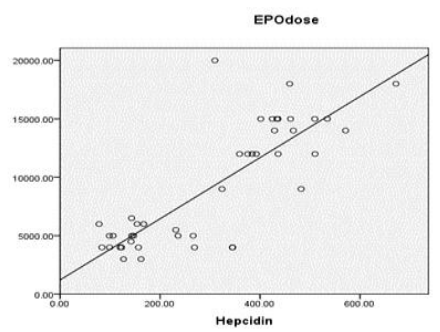

으observed

$r=0.884$
$P<0.001$

Figure 2: Correlation between hepcidin serum levels \& rhEPO dose 


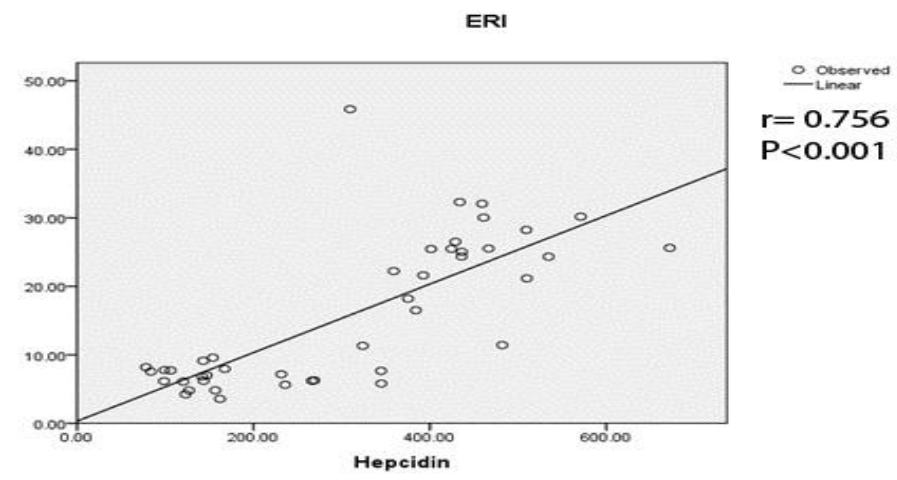

Figure 3: Correlation between hepcidin serum levels \& ERI

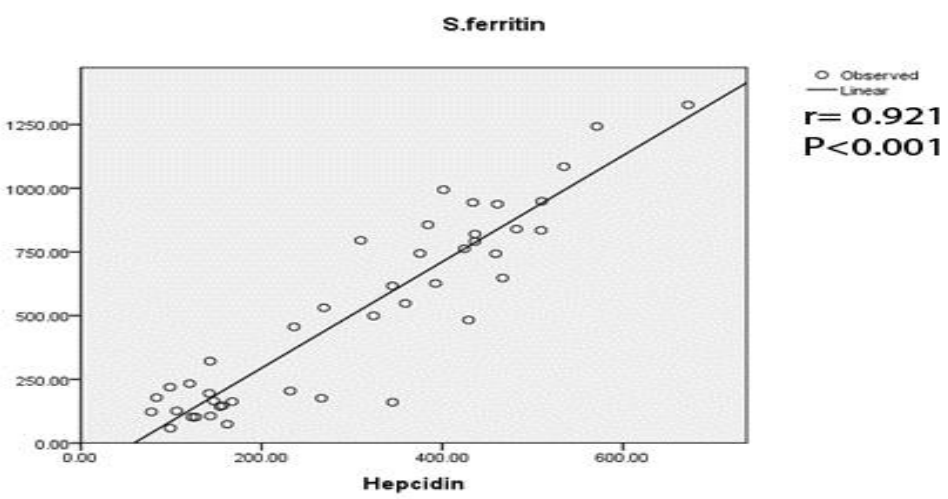

Figure 4: Correlation between hepcidin serum levels \& ferritin serum levels

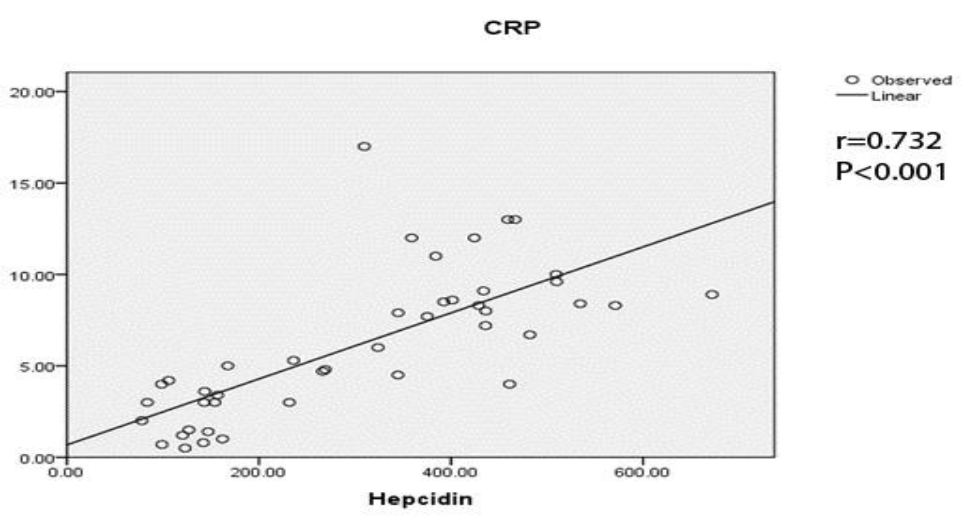

Figure 5: Correlation between hepcidin serum levels \& CRP serum levels

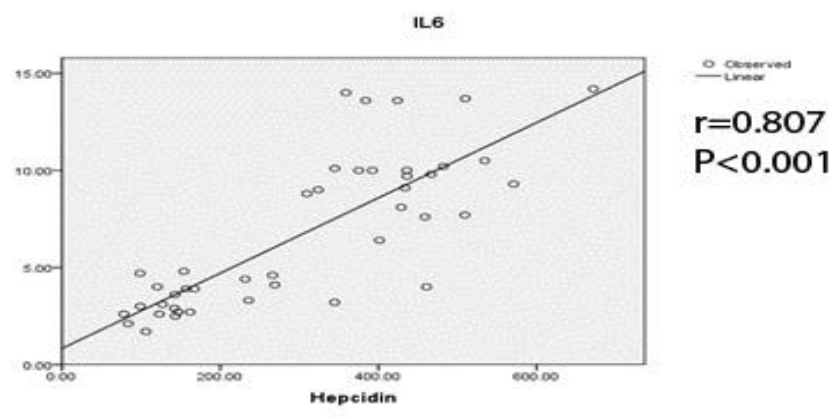

Figure 6: Correlation between hepcidin serum levels \& IL-6 serum levels 


\section{Discussion}

Anaemia in maintenance HD patients is a multifactorial condition and its clinical management remains challenging. The interactions between iron metabolism, EPO deficiency and chronic inflammation are difficult to dissect and new markers are urgently needed to optimize treatment approaches [10] hepcidin might potentially be used as a clinical marker to optimize treatment approaches in several systemic iron disorders because of its main biological role is in the regulation of body iron homeostasis through interactions with ferroportin [11,12] Hepcidin is also induced by inflammation, which is believed to be part of the host defense mechanism to fight infection and cancer by limiting iron availability $[13,14]$

In agreement with these data, the present study demonstrated that HD patients had higher hepcidin serum levels as well as higher levels of markers of chronic inflammation such as ferritin, CRP and IL-6 than in healthy control subjects. Our results suggest that the high levels of hepcidin found in HD patients could be related to an underlying chronic inflammation.

Moreover, correlations between hepcidin and inflammatory markers (CRP and IL-6) and multiple regression analysis corroborate this finding. Among HD patients, we found that the non-responders to rhEPO therapy presented with more anaemia, higher ERI values \& higher rhEPO doses compared to responders and statistically significant differences were found in the serum iron status markers between the groups of patients which were higher among non-responders but all markers were above the normal reference values. Most patients with insufficient response to rhEPO, however, have normal or elevated ferritin levels and TSAT, and are therefore considered to be functionally iron deficient. The currently used parameters of iron metabolism, such as TSAT and ferritin, did not predict this response [15].Various studies have shown a good correlation between serum hepcidin and ferritin. Serum levels of both parameters are elevated in (low grade) inflammatory diseases such as HD and decreased in iron deficiency. Hepcidin has several advantages: (i) it directly reflects iron availability and needs for erythropoiesis and (ii) it integrates the input from inflammatory and erythropoietic pathways and better reflects the status of iron homeostasis than single parameters such as TSAT, sTfr and CRP [16]. The effects of inflammation on the synthesis of hepcidin are well understood and are mediated, at least in part, by IL-6 through induction and binding of signal transducer and activator of transcription 3 (STAT 3) to the hepcidin gene promoter [17] .

There was a significant positive correlation between serum IL-6 \& CRP and serum hepcidin levels in the present study, which would seem to support this proposed mechanism. Previous studies have shown that comparison between hepcidin and CRP may serve as a quick and easy method for identifying the difference between iron deficiencies, micro inflammation or mixed anaemia [18]. In addition to its effect on iron metabolism; hepcidin may contribute to rhEPO resistance through a direct inhibitory effect on erythroid progenitor proliferation and survival [5]. Other studies revealed contradictory results; Kato et al. [19] found hepcidin levels were not different between rhEPO-responsive and rhEPO resistant dialysis patients, whereas Ford et al. [20] found no relationship of hepcidin with rhEPO dose. Over expression of hepcidin in animals impairs the response to even supra physiological doses of rhEPO [21]. It has been suggested that hepcidin play a central role in the development of rhEPO resistance. [22]. Thus, high hepcidin levels may contribute to rhEPO resistance, observed in our dialysis patients. Consequently, lowering hepcidin or inhibiting its signaling would release iron from stores, promote erythropoiesis, and prolong red cell survival, and may be safer than high doses of rhEPO with repetitive parenteral iron [21]. As non-responder patients present high inflammatory markers, hepcidin serum levels increased. Recently it has been demonstrated that erythropoietin down regulates liver hepcidin expression, acting, therefore, as a hepcidin inhibitory hormone [16].Since non-responders were treated with much higher doses of rhEPO compared with responders, the high hepcidin levels among non responders could be explained, despite the treatment with high doses of rhEPO, by the fact that the stimulus of inflammation for hepcidin synthesis in HD patients is stronger than the inhibitory effect of rhEPO which is high in our patients. Another explanation is the possibility of erythropoiesis inhibition (ineffective erythropoiesis) by rhEPO neutralizing antibodies so, Hepcidin was not suppressed. Direct suppressing hepcidin transcription via small-interfering RNA has also been shown in preclinical studies to lower hepcidin, enhance erythropoiesis and increase in serum iron levels [21]. Human trials of this latter technology are expected to take place in the coming years. There were some limitations to the present study. First, it was limited by the cross-sectional design, and secondly, the study was limited by the sample size.

\section{Conclusion:}

Serum hepcidin levels were associated with iron status \& micro inflammation and resistance to rhEPO therapy. Measurement of other biochemical markers as IL-6 and CRP may be useful in prediction of resistance to rhEPO therapy in maintenance hemodialysis patients. It may be necessary to enlarge the study groups in order to obtain more significant conclusions and to evaluate the role of these parameters in the response to rhEPO therapy 


\section{References}

[1]. Weiss G, Theurl I, Eder S, et al, Serum hepcidin concentration in chronic haemodialysis patients: associations and effects of dialysis, iron and erythropoietin therapy, Eur. J. Clin. Invest., 2009; 39: 883 - 890.

[2]. KDOQI, National Kidney Foundation: KDOQI clinical practice guidelines and clinical practice recommendations for anaemia in chronic kidney disease, Am. J. Kidney Dis., 2006; 47(5suppl 3): S11 - S145.

[3]. Locatelli F, Aljama P, Barany P, Canaud B, Carrera F, Eckardt KU, Horl WH, Macdougal IC, Macleod A, Wiecek A and Cameron S. European Best Practice Guidelines Working Group. Revised European best practice guidelines for the management of anemia in patients with chronic renal failure, Nephrol. Dial. Transplant. 2004; 19 [Suppl 2]: ii1-ii47.

[4]. Joshua Zaritsky et al,: Hepcidin-A Potential Novel Biomarker for Iron Status inChronic Kidney Disease, Clin. J. Am. Soc. Nephrol., 2009; 4: 1051-1056,

[5]. Dallalio G, Law E and Means RT, Hepcidin inhibits in vitro erythroid colony formation at reduced erythropoietin concentrations, Blood, 2006; 107:2702-2704

[6]. Nicolas G, Viatte L, Bennoun M, Beaumont C, Kahn A and Vaulont S, Hepcidin, a new iron regulatory peptide, Blood Cells Mol. Dis., 2002; 29: 327-353.

[7]. Gunnell J, Yeun JY, Depner TA and Kaysen GA, Acute-phase response predicts erythropoietin resistance in hemodialysis and peritoneal dialysis patients, Am. J. Kidney Dis., 1999, 33: 63-72.)

[8]. Ganz T, Olbina G, Girelli D, Nemeth E and Westerman, M, Immunoassay for human serum hepcidin, Blood, 2008; 112: 42924297.

[9]. Tugirimana PL, Holderbeke AL, Kint JA and Delanghe JRA, New turbidimetric method for assaying serum C-reactive protein based on phosphocholine interaction, Clin. Chem. Lab. Med., 2009; 47(11):1417-22..

[10]. Swinkels DW and Wetzels JF, Hepcidin: a new tool in the management of anaemia in patients with chronic kidney disease, Nephrol. Dia.1 Transplant. 2008; 23:2450-2453.

[11]. Nicolas G, Viatte L, Bennoun M, et al, Hepcidin, a new iron regulatory peptide, Blood Cells Mol. Dis., 2002; $29: 327$ - 335.

[12]. Nemeth E and Ganz T, Regulation of iron metabolism by hepcidin, Annu. Rev. Nutr. 2006; $26: 323$ - 342.

[13]. Babitt JL and Lin HY, Molecular mechanisms of hepcidin regulation: implications for the anaemia of CKD, Am. J. Kidney Dis. 2010; 55: $726-741$.

[14]. Nicolas G, Chauvet C, Viatte L, et al, The gene encoding the iron regulatory peptide hepcidin is regulated by anaemia, hypoxia, and inflammation, J. Clin. Invest., 2002; 110: $1037-1044$.

[15]. Singh AK, Coyne DW, Shapiro W, et al., (DRIVE Study Group), Predictors of the response to treatment in anemic hemodialysis patients with high serum ferritin and low transferrin saturation, Kidney Int., 2007; 71:1163-1171.

[16]. Costa E, Pereira BJG, Rocha-Pereira P, Rocha S, Reis F, Castro E, Teixeira F, Miranda V, Sameiro Faria M, Loureiro A, Quintanilha A, Belo L and Santos-Silva A, Role of prohepcidin, inflammatory markers and iron status in resistance to rhEPO therapy in hemodialysis patients, Am. J. Nephrol., 2008; 28: 677-683.

[17]. Wrighting DM and Andrews NC, Interleukin-6 induces hepcidin expression through STAT3, Blood, 2006; 108: 3204 - 3209.

[18]. Sasu BJ, Li H, Rose MJ, et al, Serum hepcidin but not prohepcidin may be an effective marker for anaemia of inflammation (AI), Blood Cells Mol. Dis., 2010; 45: 238 - 245.

[19]. Kato A, Tsuji T, Luo J, et al., Association of prohepcidin and hepcidin-25 with erythropoietin response and ferritin in hemodialysis patients, Am. J., 2008; 28: 115-121.

[20]. Ford B, Eby C, Scott M, et al., Intra-individual variability in serum hepcidin precludes its use as a marker of iron status in hemodialysis patients, Kidney Int., 2010; 78: 769-773.

[21]. Sasu BJ, Cooke KS, Arvedson TL, et al., Antihepcidin antibody treatment modulates iron metabolism and is effective in a mouse model of inflammation-induced anemia, Blood, 2010; 115: 3616-3624.

[22]. Singh AK, Coyne DW, Shapiro W and Rizkala AR, Predictors of the response to treatment in anemic hemodialysis patients with high serum ferritin and low transferrin saturation, Kidney Int., 2007, 71: 1163-1171. 